\title{
МАЛОИНВАЗИВНАЯ КОРРЕКЦИЯ ГЕМИФАЦИАЛЬНОЙ ДЕФОРМАЦИИ СИНДРОМА ГОЛЬДЕНХАРА. ОПИСАНИЕ КЛИНИЧЕСКОГО СЛУЧАЯ
}

\author{
Л.Н. Яковенко, В.П. Ефименко, О.Б. Шафета \\ Национальный медицинский униВерситет им. А.А. Богомольца \\ Кафредра хирургической стоматологии ч челюстно-лицеВой хирургии детского возраста
}

\begin{abstract}
Основной проблемой пациента с синдромом Гольденхара (СГ) является гемифациальная асимметрия. Диффференцированный подход в лечении таких больных позволяет избежать многоэтапности и чрезмерной травматичности хирургических вмешательств. Современные технологии СКТ и CAD/CAM позволяют провести высокоинформативное диагностическое обследование и компьютерное моделирование самой операции с виртуальной визуализацией результатов. В педиатрической хирургии надо отдавать предпочтение малоинвазивным методам лечения, которые позволяют достичь максимального результата с учетом всех клинических проявлений в корреляции с возрастом пациента и сокращением сроков его реабилитации.

КлючеВые слова: гемифачиальня деформачия, синдром Гольденхара, лечение.
\end{abstract}

Синдром 1-2 жаберных дуг (гемифрациальная микросомия, окулоаурикуловертербральный синдром, синдром Гольденхара) - собирательное понятие, подразумевающее врожденное, выраженное в различной степени одно- или двустороннего недоразвития структур лица, фрормирующихся из тканей 1-й и 2-й жаберных дуг [2, 3, 6]. Гемифациальная микросомия - наиболее часто встречающаяся форма изолированной лицевой асимметрии, которая занимает второе место после несращений верхней губы и неба $[1,4,5]$. Клинические проявления синдрома 1-2 жаберных дуг отмечаются уже в раннем возрасте и могут варьировать от едва заметной асимметрии лица до тяжелых форм одностороннего недоразвития, включающих недоразвитие орбиты, ушной раковины (вплоть до полного ее отсутствия), нижней и верхней челюстей, височной кости, скуловой дуги [5-7]. Диагностика синдрома Гольденхара (СГ) проводится в соответствии с современными классификациями с применением всего диагностического арсенала $[1,2,5,6]$. Лечение таких пациентов многоэтапное, комплексное с учетом клинической характеристики и возрастного аспекта. Хирургические вмешательства требуют тщательного планирования с использованием СKT и CAD/CAM-технологий для минимизации инвазивности каждого этапа [7-9].

Материалы и методы. Пациент - ребенок с СГ, фотометрия, СКТ, CAD/CAM-модель, компьютерное моделирование, индивидуальный титановый имплантат, титановые винты.
Клинический случай. Ребенок М., 15 лет поступил в клинику ЧЛО ДКБ № 7 г. Киева с жалобами на асимметрию лица справа. При клиническом осмотре: лицо асимметрично за счет уплощения правой половины лица, умеренного дефицита мягких тканей лица и уменьшении правой половины подбородка. Открывание рта свободное с незначительной девиацией нижней челюсти вправо. Прикус ортогнатический, протетическая плоскость инклинирована. Отмечается правосторонняя анотия с сохранением элемента мочки раковины и костной проводимости. Из анамнеза: ребенку на протяжении последних 5 лет была проведена серия операций по восстановлению анатомии ушной раковины, но безрезультатно (фото 1, 2).

Ребенку проведено СКТ с мультипланарной реконструкцией, которая показала недоразвитие ветви/тела нижней челюсти справа с десрицитом

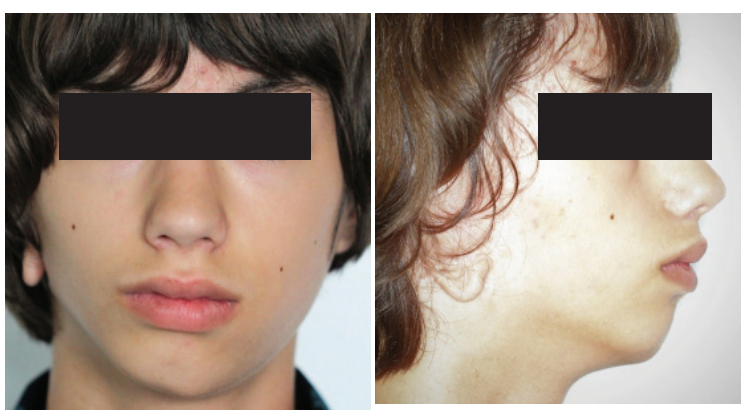

Фото 1, 2. Фото ребенка после серии операций по восстановлению анатомии ушной раковины 
11,8/13,9 мм, ментальное отверстие дистопировано вверх на 20 мм от края челюсти. Костные структуры правого ВНЧС сохранены, головка нижней челюсти незначительно уменьшена и уплощена, ментальный бугорок справа на выступе уплощен и не выражен, суставная щель сохранена и расширена на всем протяжении (фоото 3-0).

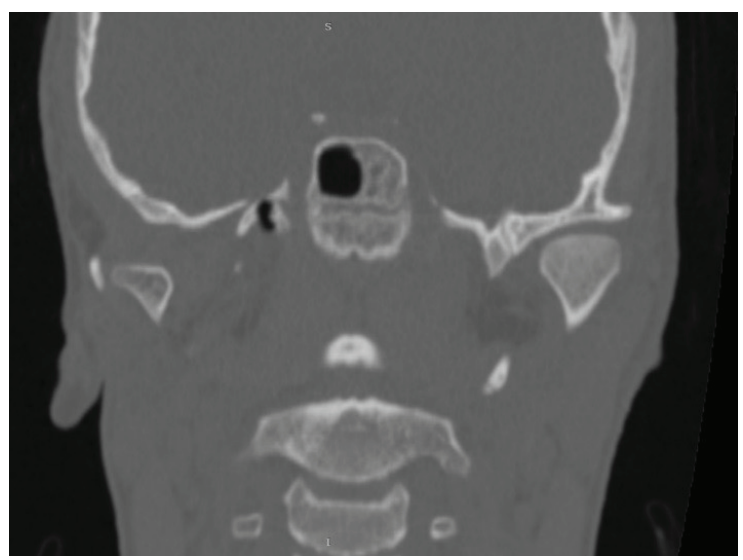

Фото 3, 4. СКТ ребенка с мультипланарной реконструкцией

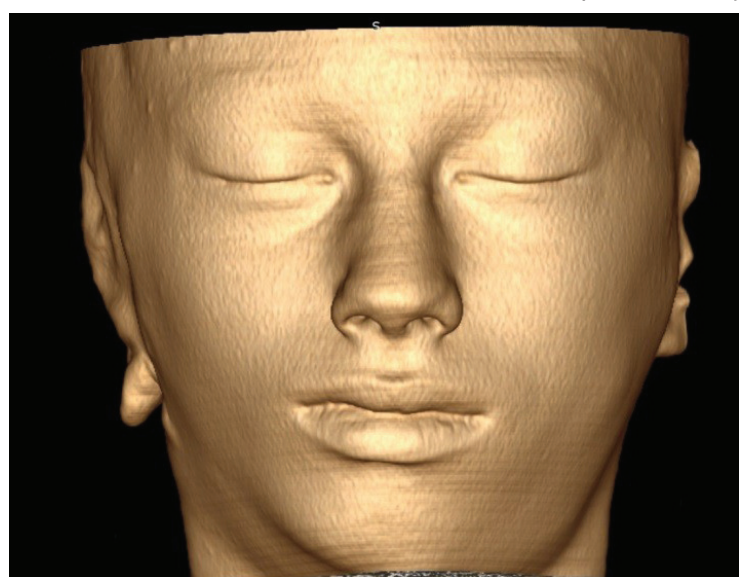

Фото 5, 6. СКТ ребенка с мультипланарной реконструкцией

У ребенка по классификации OMENS OOM1E3N0S1, по классификации Pruzansky и Kaban - 1 степень, SAT - S1A3T1. Учитывая, что функция и костные структуры правого ВНЧС сохранены, прикус ортогнатический, а основная жалоба сводится к асимметрии лица справа в области тела нижней челюсти и возраст ребенка только 15 лет, была избрана хирургическая тактика, включающая использование

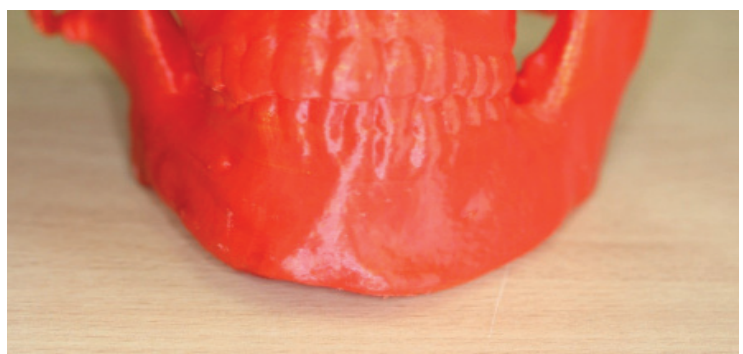

Фото 7. Стереолитографическая модель для индивидуального моделирования титанового имплантата

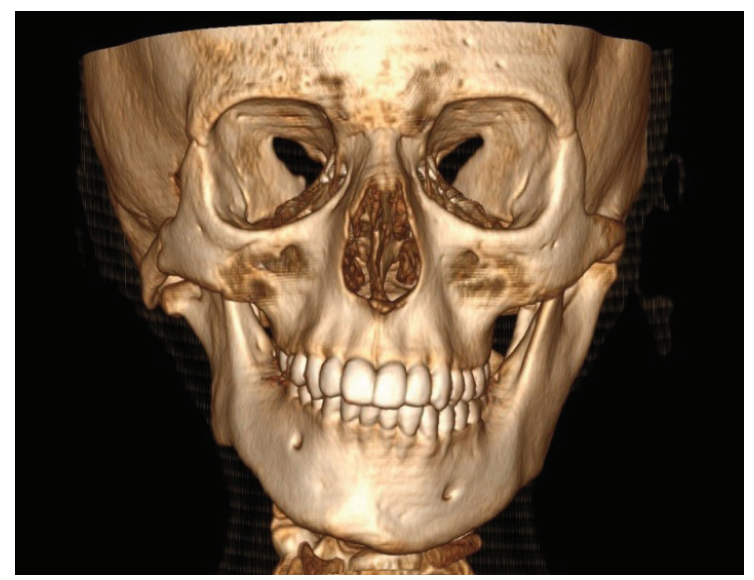

титанового эндопротеза индивидуального изготовления на нижнюю челюсть.

Мы изготовили стереолитографическую модель, используя CAD/CAM-технологию, оценили степень недоразвития челюсти и возможность ее коррекции за счет индивидуального моделирования титанового имплантата (фото 7, 8).

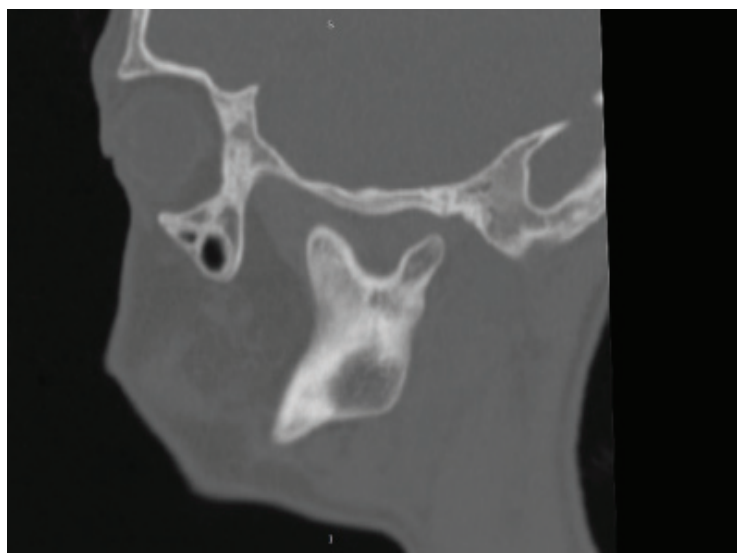

Данный метод имел несколько преимуществ: он малоинвазивен, мы добивались основной цели - нивелировали асимметрию лица, не нарушая имеющихся окклюзионных взаимоотношений.

3D-модель с результатами СКТ была обработана инженерами в лаборатории НИИ Проблем Материаловедения им. И.М. Францевича НАНУ для создания проекта титанового имплантата на правую половину тела челюсти. Анализ полученной первоначальной виртуальной титановой конструкции на 3D-модели показал, что она была громоздкой и изготовленной без учета клинической ситуации, а именно: степени недоразвития костной ткани нижней челюсти, объема мягкотканого ложа и возможностей фиксации конструкции на кости (фоото 9, 10).

После повторной перепланировки был изготовлен имплантат тела нижней челюсти. Он позволил восполнить недостающий объем кости в области от угла до подбородочного возвышения включитель- 

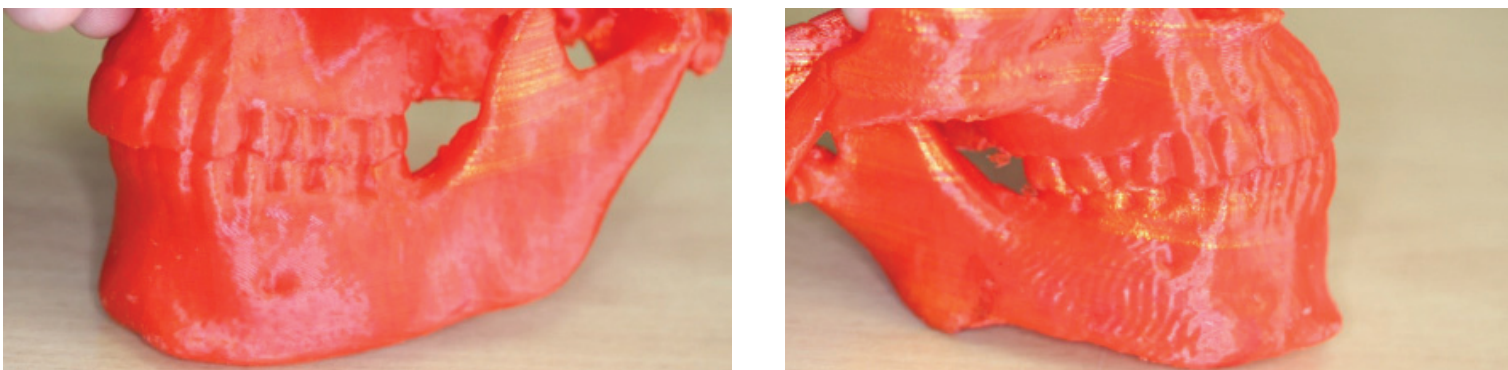

Фото 8 (а, б). Стереолитографическая модель для индивидуального моделирования титанового имплантата
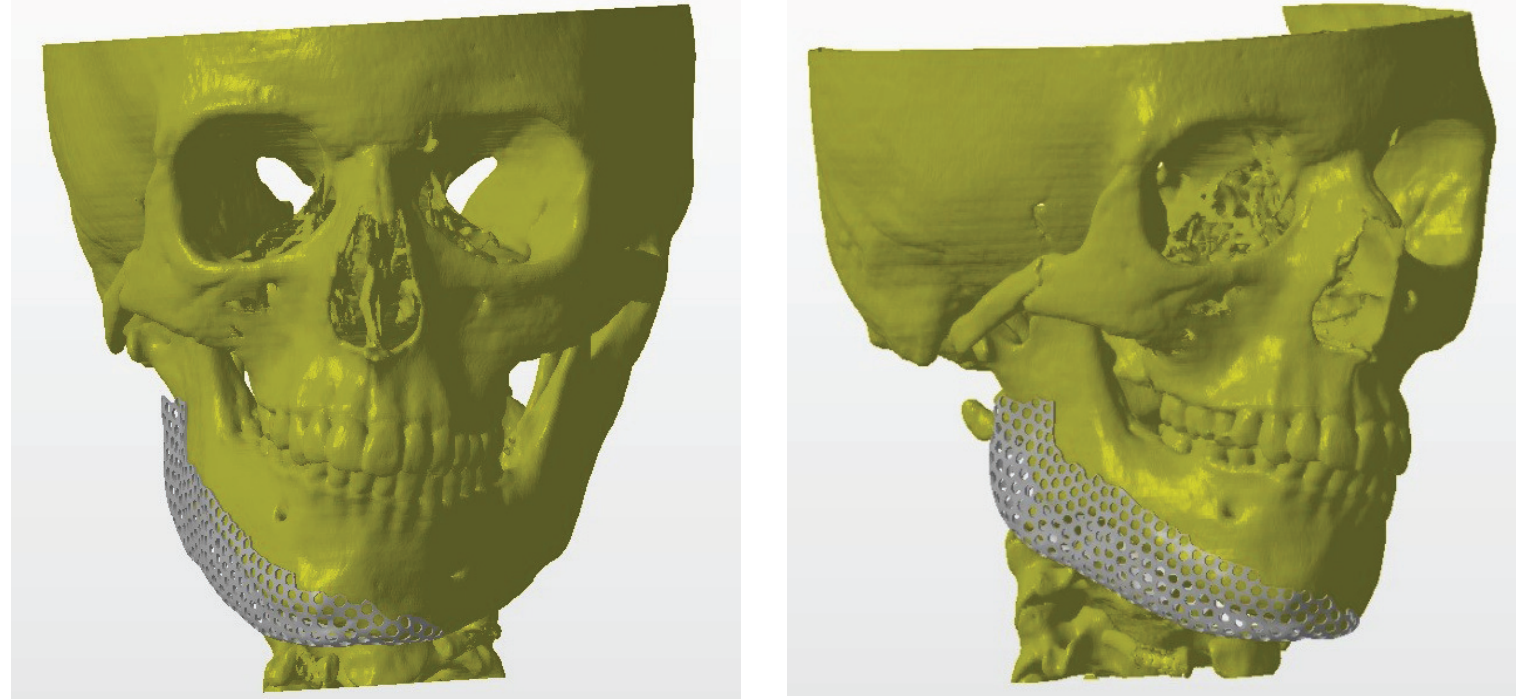

Фото 9, 10. Первоначальная виртуальная титановая конструкция на 3D-модели

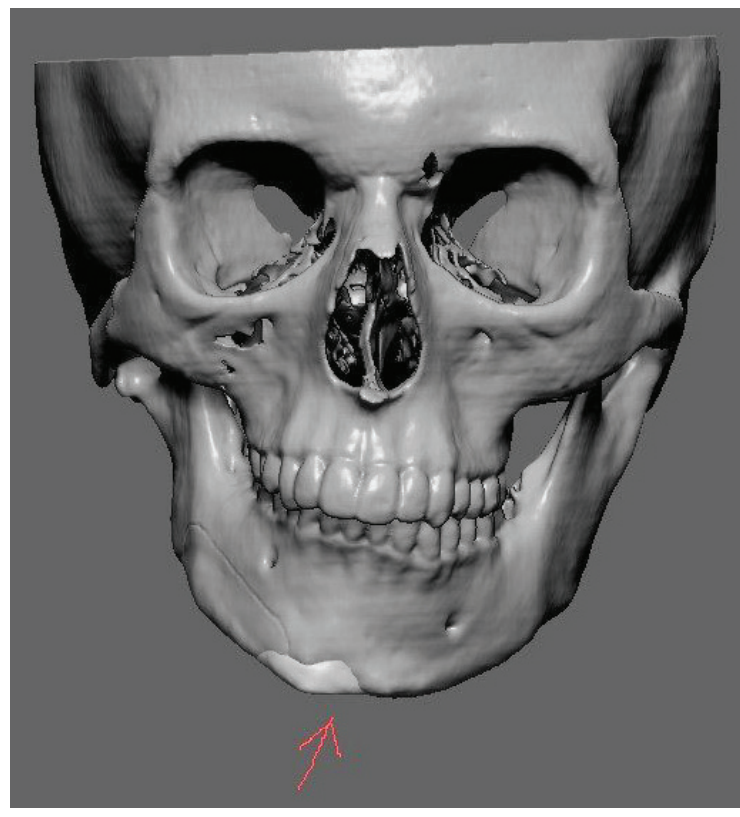

Фото 11. Имплант тела нижней челюсти

но (фоото 11), не перерастягивать мягкие ткани принимающего ложа и минимизировать травму и кости, и мягкотканного комплекса (фото 12, 13).
После общесоматической подготовки ребенка под ЭТН была проведена операция по установке титановой конструкции в виде эндопротеза. Под ЭТН подчелюстным доступом скелетирована наружная и внутренняя поверхность правой половины тела нижней челюсти от угла до подбородка, введен имплантат и позиционирован на теле челюсти в точности, как и на стереомодели до операции. После оценки точности прилегания и позиции протеза он был фриксирован в 5 точках титановыми винтами. После чего имплантат был частично укрыт надкостницей, насколько позволяла ее растяжимость, и полностью без натяжения укрыт мягкими тканями, рана была послойно ушита (фото 14-17).

Благодаря CAD/CAM-технологии по анатомическим ориентирам на 3D-модели конструкция была точно воспринята реципиентным ложе кости с четким распознаванием фиксационных пунктов, что значительно упростило техническое сопровождение и сократило время самой операции. Имплантат был максимально укрыт периостальным футляром и ушиты мягкие ткани над ним. В послеоперационном периоде пациент получал короткий курс антибактериальной терапии и кортикостероидов, курс прошел благополучно. Швы сняты на 8-е сутки. Результат операции оценен родителями и пациентом позитивно (фoomo 18-21). 

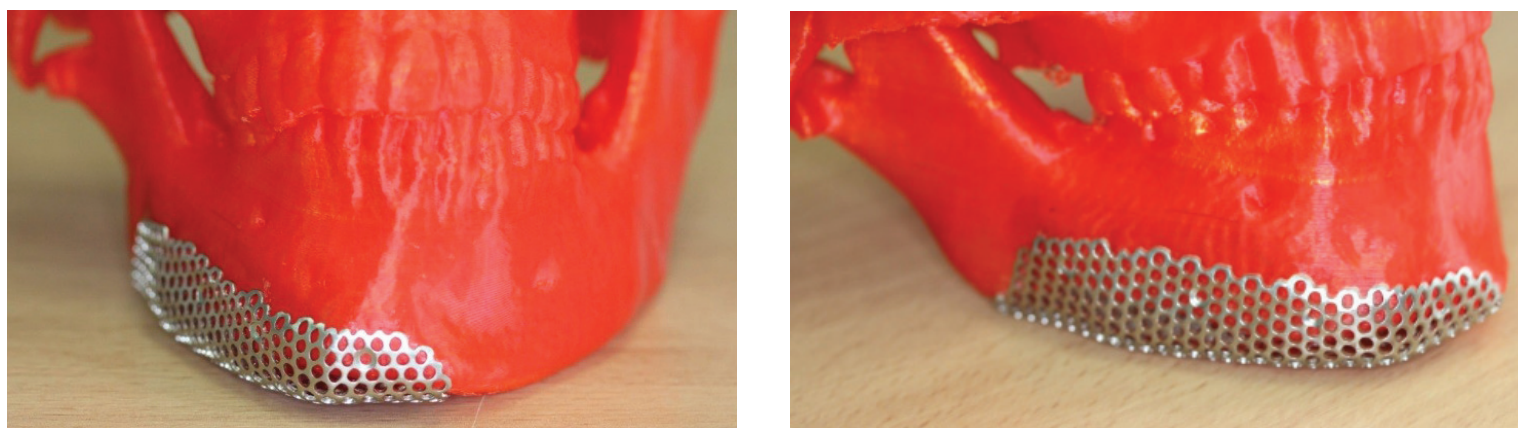

Фото 12, 13. Имплант тела нижней челюсти
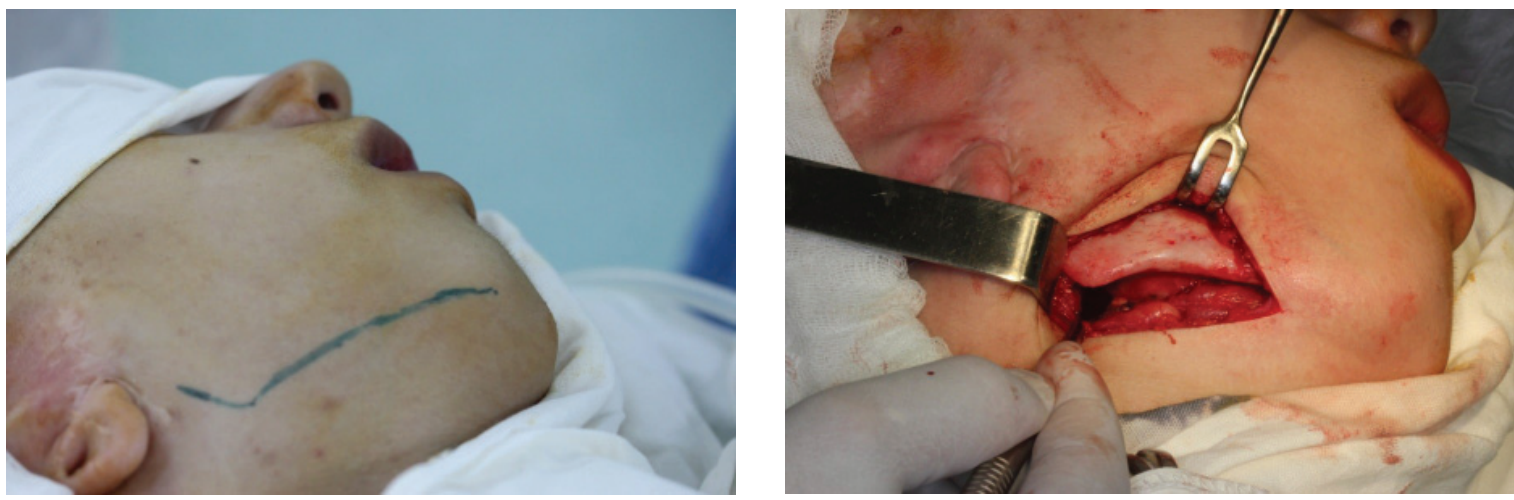

Фото 14, 15. Этапы фиксации импланта
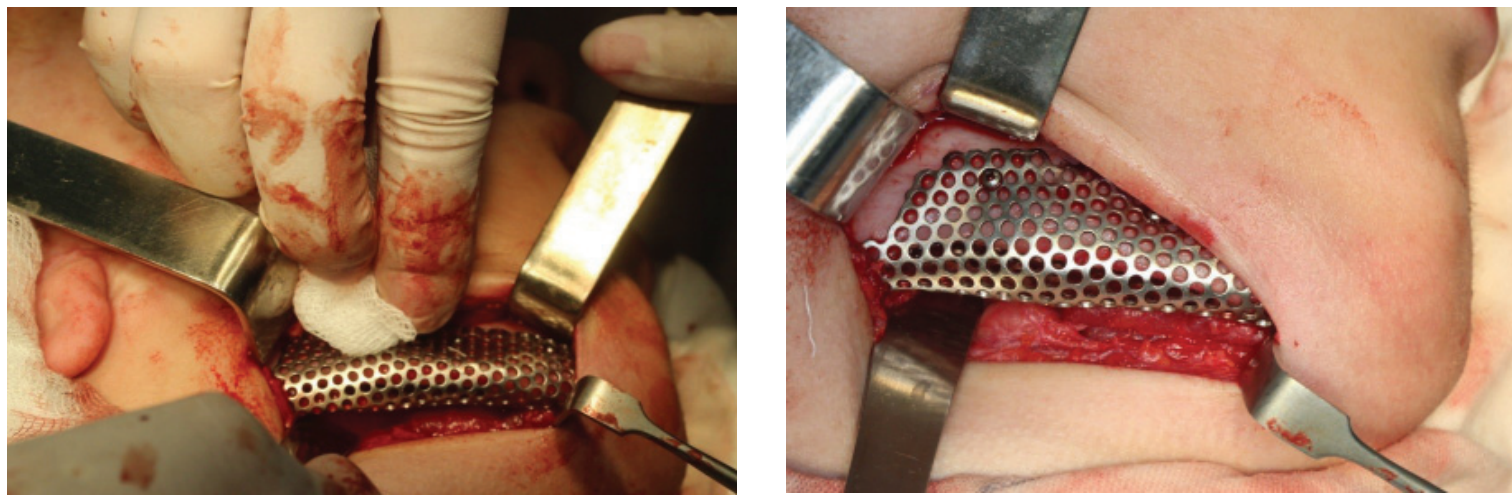

Фото 16, 17. Этапы фиксации импланта

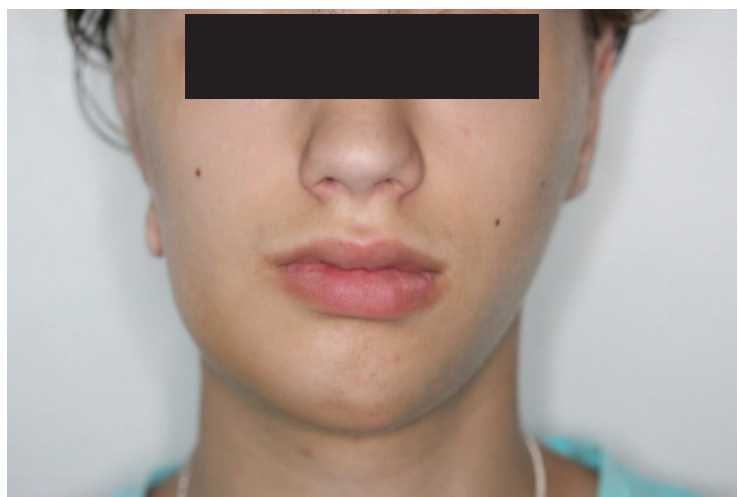

Фото $18,19$. Результат операции в различные сроки

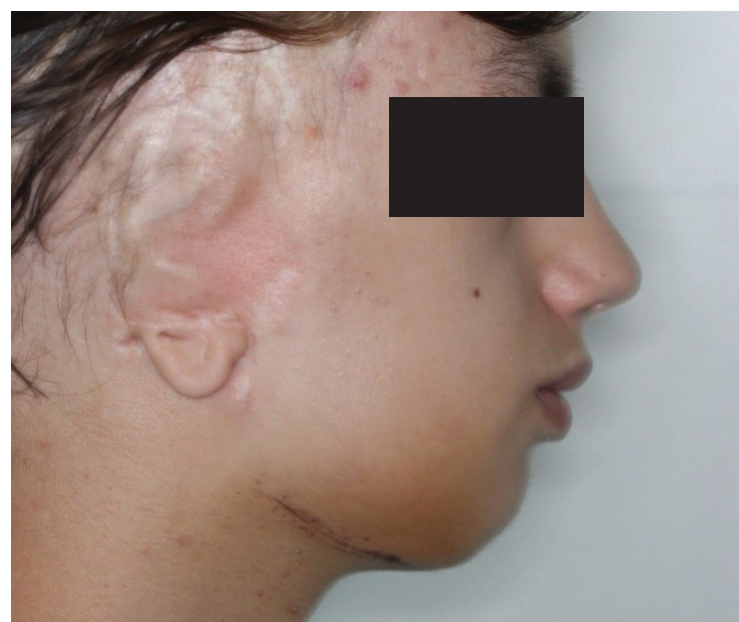



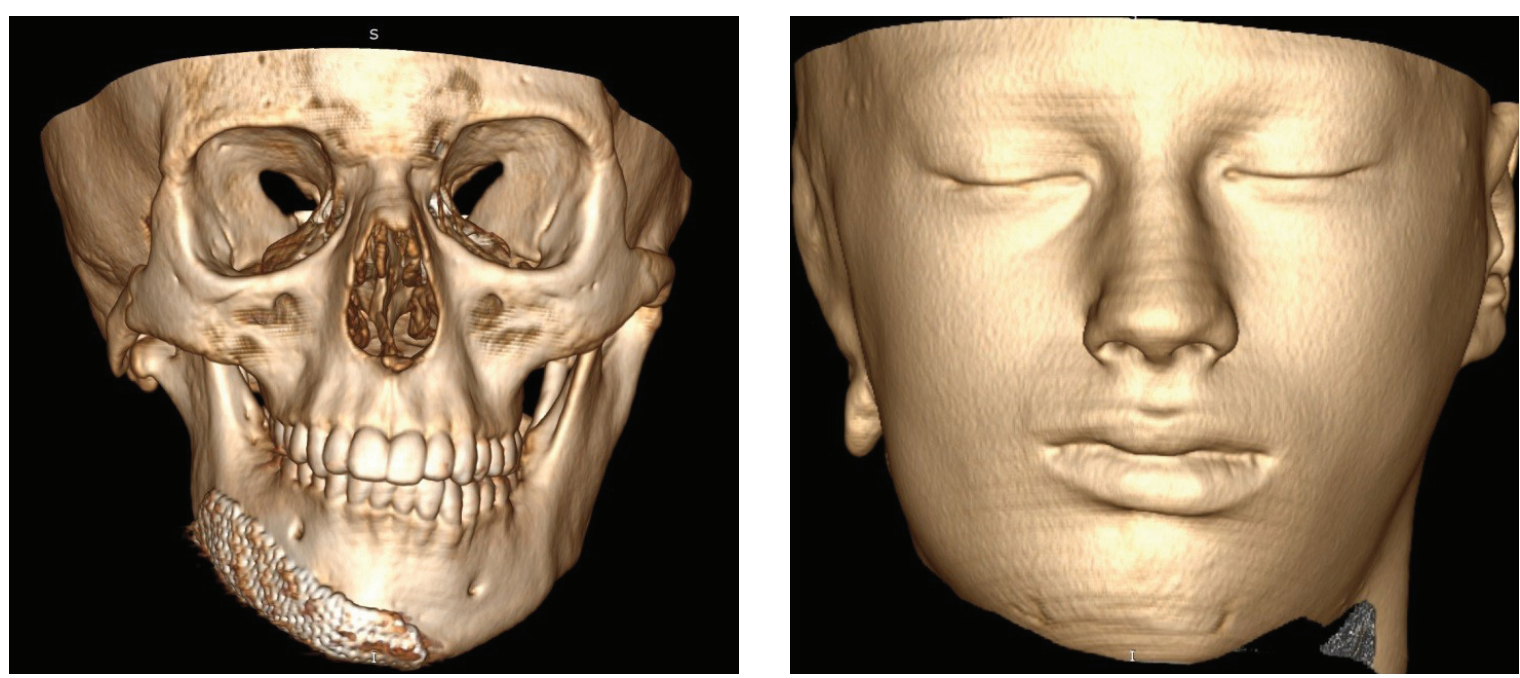

Фото 20, 21. Результат операции в различные сроки

Обсуждение. Тактика лечения пациентов с синдромом 1-2 жаберных дуг определяется степенью клинической манифестации заболевания. Современные классификации синдрома основаны на оценке степени тяжести патологии и объема пораженных структур лица. Наиболее распространенная классификация OMENS: (O - orbital distortion (поражение орбиты); M - mandibular hypoplasia (недоразвитие нижней челюсти); E - ear anomaly (аномалия уха); $\mathrm{N}$ - nerve involvement (вовлеченность нерва); S - soft-tissue deficiency (дефицит мягких тканей).

Наиболее удобна для применения в клинической практике классифрикация Pruzansky и Kaban:

- 1 степень - ветвь нижней челюсти и суставная ямка височной кости уменьшены в размере при сохранении анатомических структур;

- 2а степень - ветвь нижней челюсти, суставной отросток и суставная ямка десоормированы, но ВНЧС сохраняет свои функции; дефицит жевательной мускулатуры;

- 26 степень - недоразвитие и деформация мыщелка и суставной ямки височной кости с отсутствием функции ВНЧС;

- 3 степень - ветвь нижней челюсти, мыщелок, суставная ямка височной кости отсутствуют, т.е. ВНЧС как анатомическое образование не сформирован; наблюдается также значительный дефицит мягких тканей пораженной стороны.

Классификация SAT обращает внимание на три основных объекта: скелет (skeletal), раковина уха (auricle), мягкие ткани (soft tissue). Согласно данной классификации пороки развития скелета рассматриваются по пяти стадиям (от S1 до S5), нарушения структуры ушной раковины - по четырем (от A0 до А3); дефекты мягких тканей - по трем (от Т1 до T3). Так, самая легкая стадия заболевания - S1A0T1, тяжелые пороки развития - S5A3T3. Система SAT проигрывает в сравнении с предыдущей по отсутствию важных объектов поражения, которые в ней не отражаются.
Сравнивая эти три классификации, мы пришли к выводу, что классификация OMENS является более приемлемой, содержащей подробную рубрикацию основных проявлений синдрома, что дает возможность детального планирования и этапности лечения. Классификация же Kaban отражает лишь изменения в ВНЧС и мышцах, без учета всего комплекса нарушений формирования тех структур, которые и отражают симптомокомплекс синдрома Гольденхара.

Диагностика СГ основывается на клинике, иосновную нагрузку несут СКТ и CAD/CAM-технологии, которые позволяют хирургу правильно скоординировать свои действия, выбрать такой вид лечения, который был бы индивидуальным, оптимальным, щадящим и наиболее результативным. Для адекватной оценки тяжести поражения и составления дальнейшего плана лечения «золотым стандартом» есть проведение СКТ черепа с мультипланарной реконструкцией. Современные возможности СКТ позволяют определить степень зубочелюстных деформаций, сопровождающих СГ, детализировать диагностику в соответствии с классифрикацией. Однако наиболее важным в лечении таких больных является планирование этапов хирургического лечения. Современные подходы хирургического планирования, в основе которых лежат CAD/CAM-технологии, опирающиеся на результаты СКТ, позволяют в режиме реального времени увидеть и проанализировать костные изменения у этих пациентов, спланировать и изготовить титановые конструкции, а при необходимости провести симуляционные хирургические вмешательства на стереолитографических моделях. Кроме того, эти технологические возможности позволяют очень прецизионно изготовить эндопротезы, аппараты и имплантаты, при лечении микрогнатий разной этиологии, включая и СГ.

Лечение пациентов с синдромом 1-2 жаберных дуг предусматривает комплексность и кооперацию специалистов различного профиля (ортодонтов, челюстно-лицевых хирургов, отоларингологов), оче- 
редность взаимодействия которых определяется клиникой и возрастом ребенка. Грамотное ведение такого пациента ортодонтом уже с раннего возраста может способствовать уменьшению объема хирургического вмешательства и изменению способа лечения на челюстях.

В описанной клинической ситуации возможно применение следующих видов хирургической коррекции нижней челюсти - дистракционногокомпрессионного остеосинтеза (ДКО) или контурной пластики путем эндопротезирования. ДКО предусматривает проведние остеотомии нижней челюсти в области ветви или тела и многомесячную дистракцию фрагментов ее. Такому пациенту нужно обеспечить эффективное и длительное ортодонтическое сопровождение в послеоперационном периоде для стабилизации результата самой дистракции и меняющегося межчелюстного соотношения. Этот вариант имел сразу несколько отрицательных моментов - непрогнозируемый результат увеличения размера челюсти после дистракции, что влечет к значительным изменениям прикуса, хотя у пациента до лечения он был правильным. Кроме того, после проведенной дистракции и ортодонтического лечения возможно нарастание асимметрии лица, что связано с неравномерным ростом спровоцированных заболеванием и операцией костных структур. В таких случаях на этапе окончания роста лицевого скелета могут потребоваться реконструктивные операции на обеих челюстях, а это дополнительная травма.

Менее травматичные корригирующие операции с применением индивидуальных эндопротезов в виде титановых имплантатов на «недоразвитом» участке челюсти - вариант выбора лечения пациентов с СГ. Мы использовали именно последний вариант и изготовили индивидуальный титановый имплантат, что дало возможность получить стойкий косметический результат при минимизации травматичности вмешательства, не проводя остетомий и не нарушая зубочелюстных соотношений. Этот метод требовал тщательного планирования, на этапе которого, мы столкнулись с определенными технологическими трудностями. Первоначальная конструкция титанового эндопротеза, изготовленного по CAD/CAMтехнологии, была спроектирована зеркально по здоровой стороне челюсти, при этом на стерео-модели она имела завышенные границы. Последнее имело сразу несколько недостатков: сложное позиционирование имплантата, конструкция требовала значительного скелетирования кости челюсти и мобилизации надкостницы, в дистальных отделах она «наезжала» на m. masseter dex., что требовало ее пластики и приводило к дискорреляции всего мышечного комплекса нижней челюсти. Кроме того, объем мягких тканей принимающего ложа требовал натяжения для укрытия имплантата, что осложнило бы заживление раны и его интеграцию. Учет растяжимости и индивидуальной морфологии мягкотканного комплекса в месте, принимающего имплантат, крайне важен особенно у детей с дефицитом мягких тканей, как при СГ, а также в случае рубцовых деформаций, снижающих растяжимость тканей в области хирургического вмешательства. Нанаш взгляд, планированием изготовления имплантируемых конструкций должны заниматься не просто инженеры, а биоинженеры, которые могут предусмотреть топографо-анатомические особенности биообъекта. Поэтому мы совместно с инженерами еще раз пересмотрели виртуальную конструкцию имплантата и ремоделировали его с учетом индивидуальных особенностей челюсти и мягкотканного ложа пациента, уменьшив границы протеза, выведя его из мышечного блока, установив фиксационные пункты в технически приемлемых местах. Эти мероприятия позволили снизить коэфрфициент натяжения мягких тканей у будущего воспринимающего ложа. Исходя из опыта данной операции, для упрощения и контроля позиционирования имплантата считаем целесообразным проведение симуляционной фиксации на стереомоделях до операции и последующую ее стерилизацию для возможности работы с ней непосредственно в процессе операции.

Не менее важной проблемой является своевременная инклюзия подростка в социальную среду сверстников. Психоэмоциональные переживания взрослеющего ребенка, связанные с деформацией лица, в значительной степени влияют на фоомирование его как личности, на его социализацию. Поэтому правильно спланированное, своевременное и комплексное лечение СГ позволяет не только устранить косметические и функциональные нарушения, но и в значительной мере способствовать гармонизации психоэмоционального состояния такого ребенка, а значит и улучшить его качество жизни.

Выводы. Лечение пациентов с СГ должно быть комплексным, этапным и проходить в тесной кооперации с оториноларингологами и ортодонтами; СКТ в комбинации с CAD/CAM-технологиями позволяют выбрать оптимальную хирургическую тактику и осуществить еес помощью индивидуальныхимплантатов; в детской практике необходимо отдавать предпочтение малоинвазивным и максимально результативным хирургическим направлениям с учетом клинических проявлений и возраста ребенка для сокращения сроков лечения и реабилитации таких больных.

Перспективность исследований. Современное CKT, CAD/CAM-технологии и виртуальное моделирование дают возможность планирования малоинвазивных костно-пластических операций для лечения не только больных с СГ, но и любых костных дисплазий, а применение индивидуальных имплантационных технологий позволяет уменьшить инвазивность хирургического лечения и этапность реабилитации таких пациентов. 
Литература

1. Mehta B. Goldenhar syndrome with unusual features / B. Mehta, C. Nayak, S. Savant, S. Amladi // Indian J. Dermatol. Venereol. Leprol. - 2008. - № 74. - P. 254-256.

2. Sudarshan P. Gaurkar. Goldenhar Syndrome: A Report of 3 Cases / Sudarshan P. Gaurkar, Khushboo D. Gupta, Kirti S. Parmar, Bela J. Shah. / / Indian J. Dermatol. - 2013. - Vol. 58 (3). - P. 244.

3. Sharma Neeraj. Goldenhar syndrome / Sharma Neeraj, Passi Sidhi // Indian J. Dent. Res. - 2013. - Vol. 24. - P. 49.

4. Kaban L. Congenital Abnormalities of the temporomandibular joint / Facial Growth in Pediatric Oral and Maxillofacial Surgery. - Philadelphia: Saunders, 2004. - P. 302-339.

5. Hartsfield J.K. Review of the etiologic heterogeneity of the oculo-auriculo-vertebral spectrum (Hemifacial Microsomia) / J.K. Hartsfield // Orthod. Craniofac. Res. - 2007. - Vol. 10. - P. 121-128.

6. Kokavec R. Goldenhar syndrome with various clinical manifestations / R. Kokavec / / Cleft. Palate Craniofac. J. - 2006. - Vol. 43. - P. 628-634.

7. Maan M.A. Goldenhar syndrome: case reports with review of literature / M.A. Maan, G. Saeed, S.J. Akhtar, J. labal // JPAD. - 2008. - Vol. 18. - P. 53-55.

8. Lima M.D. Distraction osteogenesis in Goldenhar Syndrome: case report and 8-year follow-up / M.D. Lima, Y.M. Marques, S.M. Jr. Alves et al. // Med. Oral. Patol. Oral. Cir. Bucal. - 2007. - Vol. 12 - P. E528-E531.

9. Lima Mde D. Distraction osteogenesis in Goldenhar syndrome: case report and 8-year follow-up / Mde D. Lima, Y.M. Marques, M. Jr. Alves Sde et al. // Med. Oral. Patol. Oral. Cir. Bucal. - 2007 - Vol. 12. P. E528-E531.

10. Santamaria E. Mandibular microsurgical reconstruction in patients with hemifacial microsomia / E. Santamaria, C. Morales, J.A. Taylor et al. // Plast. Reconstr. Surg. - 2008. - Vol. 122. - P. 1839-1849.

\section{Л.М. Яковенко, В.П. Єрименко, О.Б. Шафрета}

\section{МАЛОІНВАЗИВНА КОРЕКЦІЯ ГЕМІФАЦІАЛЬНОЇ ДЕФОРМАЦІЇ СИНДРОМУ ГОЛЬДЕНХАРА. ОПИС КЛІНІЧНОГО ВИПАДКУ}

Основною проблемою пацієнта з СГ $є$ геміфаціальна асиметрія. Диференційований підхід в лікуванні таких хворих дозволяє уникнути багатоетапності і надмірної травматичності хірургічних втручань. Сучасні технології CKT і CAD/CAM дозволяють провести високоінформативне діагностичне обстеження і комп'ютерне моделювання самої операції з віртуальною візуалізацією результатів. У педіатричній хірургії треба віддавати перевагу малоінвазивним методам лікування, які дозволяють досягти максимального результату з урахуванням всіх клінічних проявів в кореляції з віком пацієнта і скороченням термінів його реабілітації.

Ключові слова: геміфачіальна деформачія, синдром Гольденхара, лікування.

L.N. Yakovenko, V.P. lefymenco, O.B. Shafeta

\section{MINIMALLY INVASIVE CORRECTION OF HEMIFACIAL DEFORMITY OF GOLDENHAR SYNDROME. CLINICAL CASE}

The main problem of a patient with SG is hemifacial asymmetry. A differentiated approach in the treatment of such patients allows us to avoid a multistep and excessive trauma of surgical interventions. Modern technologies of SCT and CAD/CAM allow for highly informative diagnostic examinations and computer simulations of the operation itself with virtual visualization of the results. In pediatric surgery, it is necessary to give preference to minimally invasive methods of treatment, which allow achieving the maximum result, taking into account all clinical manifestations in correlation with the patient's age and shortening the time of his rehabilitation.

Keywords: hemifacial deformity, Goldenhar syndrome, treatment.

\section{Контактная информация}

Яковенко Людмила Николаевна - д-р мед. наук, професор, заведующая кафедрой хирургической стоматологии и челюстно-лицевой хирургии детского возраста НМУ им. О.О. Богомольца

Адреса: Україна, м. Київ , вул. Підвисоцького, 4-Б

Тел.+38-044-484-22-06

E-mail: yakovenko_In@ukr.net

ORCID: 0000-0002-4145-5189

Ефименко Владислав Петрович - канд. мед. наук, доцент, кафедры хирургической стоматологии и челюстно-лицевой хирургии детского возраста НМУ им. О.О. Богомольца

Шафрета Олег Борисович - асистент кафедры хирургической стоматологии и челюстно-лицевой хирургии детского возраста НМУ им. О.О. Богомольца 